6. Трофименко С.В. Моделирование в теории случайных процессов средствами Excel. - Нерюнгри: Изд-во технического института, 2007. 78 с.

7. Трофименко С.В. Методы и примеры статистических оценок временных рядов. - Нерюнгри: Изд-во Технического института (ф) СВФУ, 2012. 81 с.

8. Трофименко С.В., Гриб Н.Н. Элементы математических моделей в теории и практики случайных процессов. - Нерюнгри: Изд-во Технического института (ф) СВФУ, 2013. 194 с.

9. Трофименко С.В., Рябинкин К.С., Пупатенко В.В. Изучение спектров микросейсм до и после землетрясений // Успехи современного естествознания. - 2016. - № 11-1. - C. 191-196.

11. Beauduin R. et al. The effects of the atmospheric pressure changes on seismic signals or how to improve the quality of a station // Bulletin of the Seismological Society of America. - 1996. - V. 86. - N. 6. - P. 1760-1769.

12. Demuth A., Ottemöller L., Keers H. Ambient noise levels and detection threshold in Norway // Journal of Seismology. - 2016. - V. 20. - N. 3. - P. 889-904. DOI: 10.1007/s10950-016-9566-8

13. Peterson J. Observations and modeling of seismic background noise. USGS OpenFile Report 93-322 / Albuquerque: U.S. Geological Survey, 1993. 94 p.

\title{
Разработка мультимедийных практических работ к урокам окружающего мира в начальной школе посредством языка программирования ACTIONSCRIPT
}

\section{Саввинов Е.В., студент, Вилюйский педагогический колледж им. Н.Г. Чернышевского, 2. Вилюйск E-mail: Lenal_mrd@mail.ru}

Научные руководители: Лебедева Л.А., Петрова И.И.

Новые информационные технологии имеют огромный диапазон возможностей для совершенствования учебного процесса, в том числе и на уроках Окружающего мира в начальной школе. Одним из дидактических средств, обладающих значительным развивающим потенциалом, является мультимедиа, которые можно использовать на практических занятиях, так как их использования значительно расширяет интенсивность и возможности современного урока, повышает интерес детей.

Проблема заключается в противоречиях между потребностью ИКТсопровождения практических занятий на уроках окружающего мира в начальной школе и отсутствием эффективных материалов вследствие трудоемкости и невозможности разработки сопровождения самими учителями начальных классов.

Цель: разработка мультимедийных практических работ к урокам окружающего мира в начальной школе с помощью языка программирования ACTION SCRIPT.

Данная работа предназначено для учащихся муниципального бюджетного общеобразовательного учреждение «Вилюйская начальная школа №1» муниципального района «Вилюйский улус (район)» Республика Саха (Якутия). 
В главном меню пособия имеются 11 опытов для учащихся 3 класса по предмету «Окружающий мир». Основным инструментом для работы является кнопки для перехода к запуску всех других опытов. В главном меню содержится список опытов. Все отмечены разными цветами. Ко всем опытам сделаны соответствующие анимации со звуковым сопровождением. Сетевая гамма соответствует всем требованиям. Все детали к опытам сделаны предварительно в графическом редакторе Adobe Photoshop.

Особенность разработки мультимедийного пособия, сопровождающего практические занятия по окружающему миру, заключается в демонстрации опытов по алгоритму, аналогично проведенному в условиях лаборатории, который предполагает показывать естественные результаты как в реальных условиях.

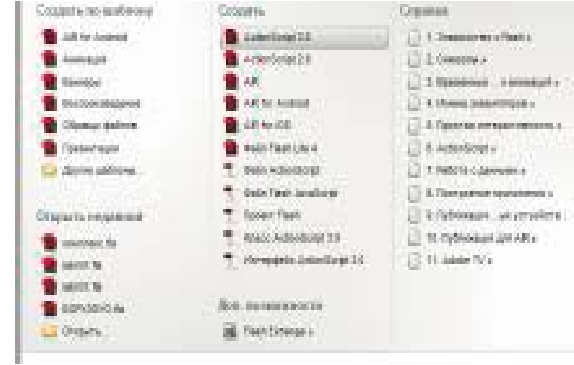

Рис. 1. Запуск программы

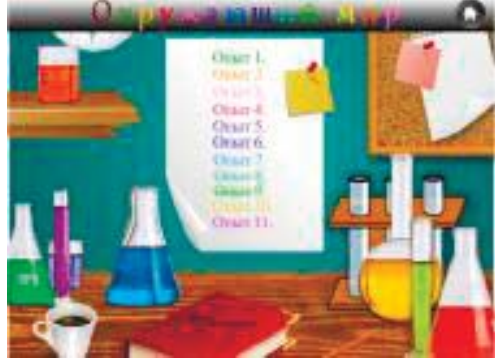

Рис. 2. Меню программы «Окружающий мир»

Разработка главной меню программы.

1. Открываем Adobe Flash создаем новый файл и сохраняем его под именем «Начало» (см.рис. 4.1. Запуск программы).

2. Рисуем фон, и заготовки для кнопок (см. рис. 4.2. Меню программы «Окружающий мир»).

3. Для создание кнопки: нарисуем объект на сцене. Преобразуем объект в символ. Для этого, используя инструмент «Selection Tool», который находится на правой панели, выбираем объект и нажимаем правую кнопку мыши, в появившемся контекстном меню выбираем «Convert to Symbol», в поле «tуре» устанавливаем»button», в поле «nаmе» дадим имя объекту «button1". Затем настраиваем кнопку, добавим на кнопку текст. Чтобы это сделать, создаем, находясь в режиме редактирования button1, на панели «timeline» еще один слой, на который мы поместим произвольный текст. Чтобы при нажатии на кнопку происходило какое-то действие, нужно внести программный код. Для этого переходим из режима редактирования кнопки в режим сцены. (см. рис. 4.3. Исходные коды).

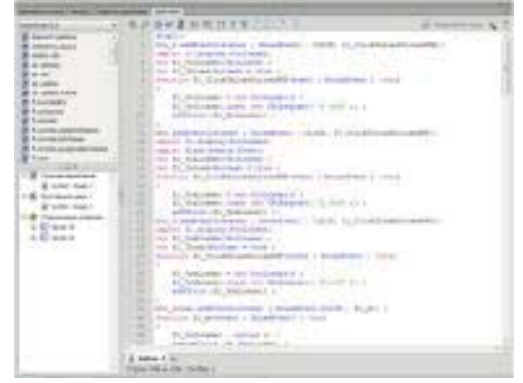

Рис. 3. Исходные коды

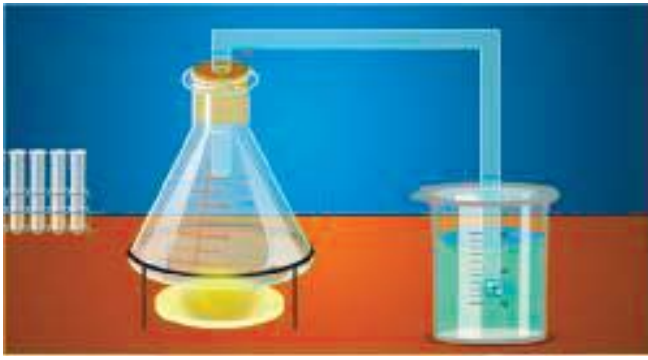

Рис. 4. Опыт 1 «Что происходит с воздухом при нагревании?»

4. При рисовании прямоугольников или овалов с помощью инструментов «Прямоугольный примитив» или «Овальный примитив» Animate создаем эти фигуры в качестве отдельных объектов. Они отличаются от объектов, созданных в режиме 
«Рисование объектов». Инструменты создания примитивов позволяют задать радиус угла прямоугольника с помощью элементов управления в инспекторе свойств. Кроме того, задали начальные и конечные углы, а также внутренний радиус овала. После создания примитивной фигуры изменили радиус и размер, выделив фигуру в рабочей области и задали нужные параметры в инспекторе свойств

Опыт №1 «Что происходим с воздухом при нагревании».

Открываем Adobe Flash создаем новый файл и сохраняем его под именем «Опыт №1».Рисуем задний фон, колбу, стакан с водой и трубки с помощью инструментов: Tools, выделения, закраски, прямоугольник, карандаш, кисть, рисования, текст. Область цветов содержит модификаторы для обводки и заливки. Затем создаем анимацию горения под колбой с воздухом.и.тп. В конце, создаем анимацию пузырьков воздуха в стакане воды (см. рис. 4.4. Опыт 1 «Что происходит с воздухом при нагревании?»).Чтобы анимировать объекты в программе Flash, необходимо создать ключевые кадры на шкале времени (Timeline). В каждом ключевом кадре программа Flash сохраняет текущее состояние сцены: положение объектов, цвет, размер, форму и другие атрибуты. Чтобы создать покадровую анимацию, необходимо создать ключевой кадр для каждого кадра и немного изменить объекты в каждом кадре. Но быстрее и проще воспользоваться преимуществами расчетной анимации движения и формы в программе Flash. В этом случае необходимо создать первый и последний ключевой кадр, а промежуточные кадры программа Flash построит автоматически.

В этом работе мы использовали две разности текста - текст “Classic” и текст TLF (Text Layout Format).

Цель опыта: узнать, что происходит с воздухом при нагревании.

Ход опыта. Возьмем колбу с трубкой и опустим трубку в воду. Заметим, что вода не входит в трубку - ее не пускает воздух. Будем нагревать колбу. Из трубки стали выходить пузырьки воздуха.

Вывод. При нагревании воздух расширяется.

Опыт №2 «Что происходим с воздухом при охлаждении».

Рисуем задний фон, колбу, стакан с водой и трубки с помощью инструментов прямоугольник, карандаш, кисть, заливка и т.п. Затем создаем анимацию горения под колбой с воздухом и подъема воды по трубке (см. рис.4.5. Опыт 2 «Что происходит с воздухом при охлаждении»).

Цель опыта: узнать, что происходит с воздухом при нагревании.

Ход опыта: Подставим под колбой лед. Мы увидим как вода будет подниматься в трубке. Воздух как бы уступает воде часть своего места.

Вывод: при охлаждении воздух сжимается.

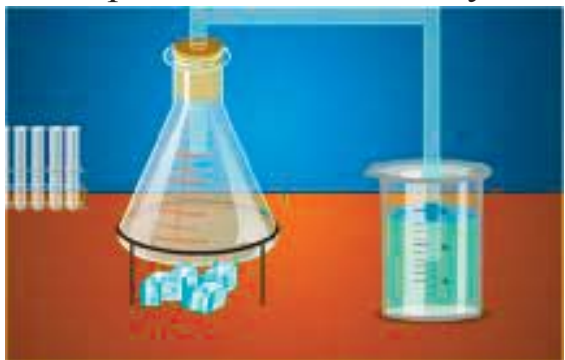

Рис. 5. Опыт 2 «Что происходит с воздухом при охлаждении»

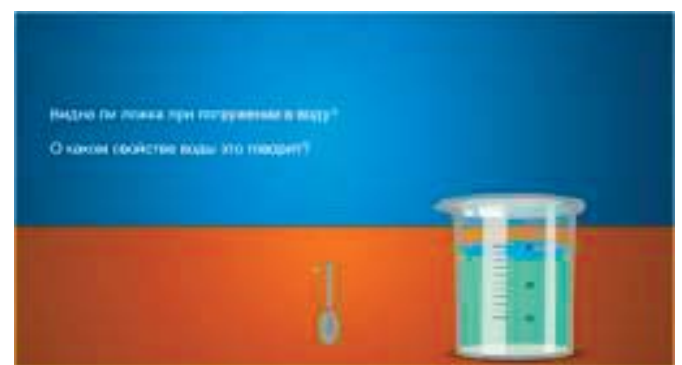

Рис. 6. «О каком свойстве воды это говорит?»

Опыт 3. Опусти в стакан с водой ложку. Видна ли она? О каком свойстве воды это говорит (см. рис. 4.6. «О каком свойстве воды это говорит?»). 
Опыт 4. Сравни цвет воды с цветом полосок, изображенных на учебнике. Имеет ли вода цвет (см.рис 4.7 «Имеет ли вода цвет?»).

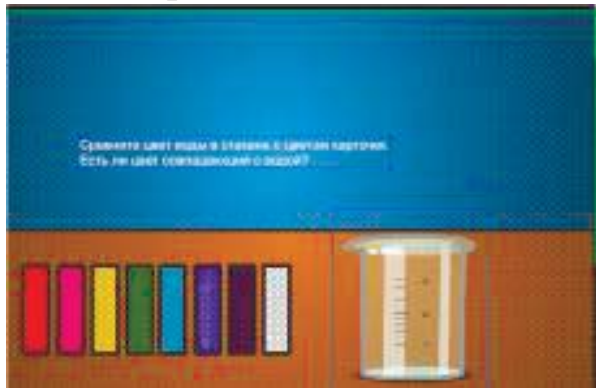

Рис. 7. «Имеет ли вода цвет»



Рис. 8. Разделение смеси

Опыт 5. Насыпь в один стакан с водой немного соли, а в другой столько же измельченного мела. Помешай. Что произошло? О чем говорит этот опыт (см.рис. 4.8. Разделение смеси).

Опыт 6. Не много свежей почты нагреем на огне. Над почвой подержим холодное стекло. Вскоре стекло станет влажным. Этот опыт показывает, что в почве есть вода (см. рис.4.9. Изучение состава почвы 1).

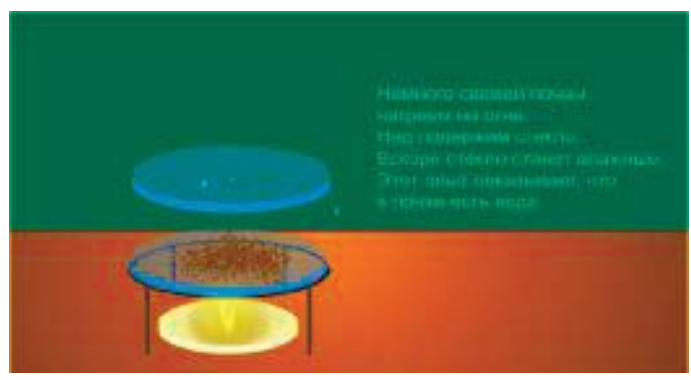

Рис. 9. Изучение состава почвы 1



Рис. 10. Изучение состава почвы 2

Опыт 7. Немного сухой почвы нагреем на огне. Вскоре мы увидим дым. Почувствуем неприятный запах. Это сгорает перегной почвы, который образовался из остатков растений и животных (см. рис. 4.10. Изучение состава почвы 2).

Опыт 8. Не много свежей почты нагреем на огне. Над почвой подержим холодное стекло. Вскоре стекло станет влажным. Этот опыт показывает, что в почве есть вода (см. рис.4.11. Изучение состава почвы).

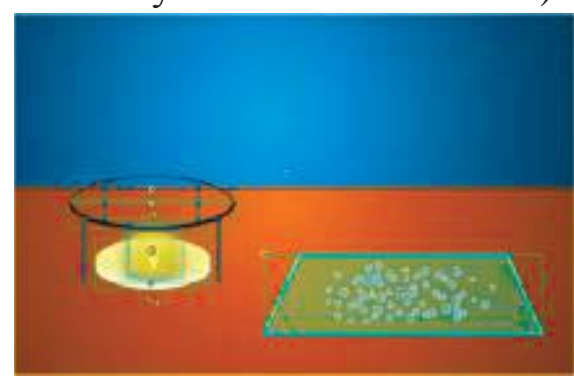

Рис. 11. Изучение состава почвы

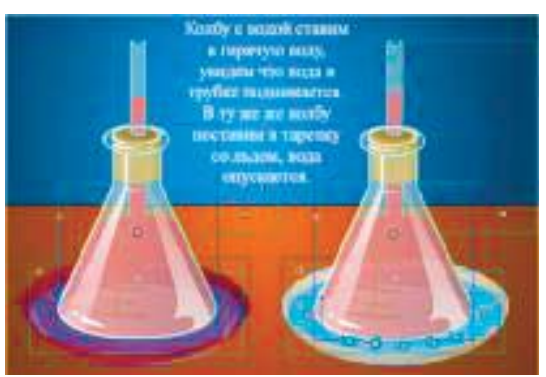

Рис. 12. Свойства воды

Опыт 9. Колбу с покрашенной водой ставим в горячую воду, увидим что вода в трубке поднимается. Ту же колбу поставим в тарелку со льдом, вода опускается (см. рис. 4.12. Свойства воды).

Опыт 10. Бросим почву в воду. Увидим что из почвы выходят пузырьки воздуха. Значит в почве есть воздух (см. рис.4.13. Состав почвы). 


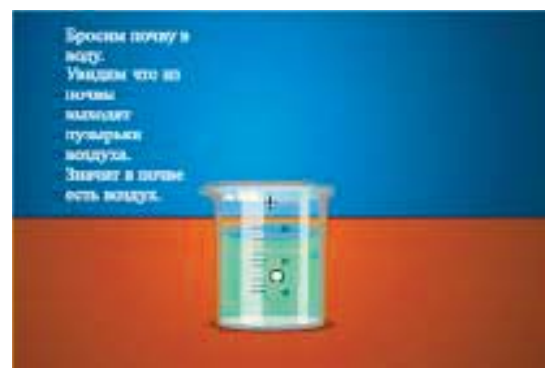

Рис. 13. Состав почвы

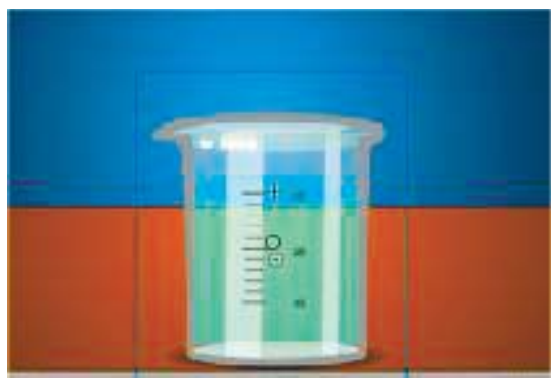

Рис. 14. Состав сахара

Опыт 11. Возьмем кусочек сахара. Опустим его в стакан с водой. Сначала сахар хорошо виден, но постепенно становится не видимым. Почему же мы не видим его? Кусочек сахара распался на мельчайшие не видимые глазом частицы, из которых он состоял и эти частицы перемешались с частицами воды (см. рис. 4.14. Состав сахара).

Проведенное исследование подтверждает нашу гипотезу о том, что использование возможностей языка программирования ACTION SCRIPT способствует повышению качества разработки мультимедийных практических работ к урокам окружающего мира в начальной школе.

Для разработки мультимедийных практических работ можно использовать программу Adobe Flash Pro CS6 и возможности языка программирования Action Script. Разработанные нами мультимедийные практические работы использованы на уроках по Окружающему миру в начальной школе № 1 г.Вилюйска и показывают свою эффективность.

\section{Список литературы}

1. Белошапка В.О языках, моделях и информатике [Текст] / В. Белошапка / Информатика и образование. - 2000.- № 6.- С. 12-16.;

2. Бирих Р.В. Компьютерные модели школьных физических задач [Текст] / Р.В. Бирих, Е.А. Еремин, В.И. Чернатынский // Информатика: прил. к газ. "Первое сентября".- 2006.- 16-30 апр. (№ 8).- С. 3-10.;

3. Бурцева Г. Обучить с помощью электронных средств: это возможно! [Электронный документ] / Г. Бурцева (http://pedsovet.su/publ/26-1-0-739). 10.01.2010.;

4. Голицына О.Л. Программное обеспечение. [Текст]: Учебное пособие / О.Л. Голицына, Т.Л. Партыка, И.И. Попов.- М.: ФОРУМ: ИНФРА-М, 2006.;

5. ГОСТ 5.3-2004 Библиографическая запись. Библиографическое описание [Текст]: Межгос. стандарт.- Введен в 2004 г. // Федеральный компонент государственных образовательных стандартов общего образования / М-во образования РФ. Ин-т образовательных систем.- М., 2004.;

6. Гузеев В.В. Планирование результатов образования и образовательная технология. [Текст] / В.В. Гузеев.- М.: Народное образование, 2000.; 